\title{
THE IMPACT OF SUPPLY PHASE SHIFT ON THE THREE PHASE INDUCTION MOTOR OPERATION
}

\author{
Aderibigbe Adekitan $^{1 *}$ - Ayodeji S.O. Ogunjuyigbe ${ }^{2}-$ Temitope R. Ayodele $^{2}$
}

${ }^{1}$ Department of Electrical and Information Engineering, College of Engineering, Covenant University, Ogun, Nigeria ${ }^{2}$ Department of Electrical and Electronic Engineering, Faculty of Engineering, University of Ibadan, Oyo State, Nigeria

\begin{tabular}{l}
\hline ARTICLE INFO \\
\hline Article history: \\
Received: 24.09 .2017$. \\
Received in revised form: 17.12 .2017$. \\
Accepted: 12.01 .2018$. \\
\hline Keywords: \\
Phase angle shift \\
Zero, negative and positive sequence component \\
Motor performance characteristics \\
Voltage unbalance \\
Phase frame analysis \\
Three phase induction motor \\
\hline DOI: htp:/loi.rg/10.30765/er.39.3.08
\end{tabular}

DOI: http://doi.org/10.30765/er.39.3.08

\section{Introduction}

Voltage unbalance is a poly-phase voltage supply phenomenon. Poly-phase system voltages are rarely perfectly balanced, but when voltage unbalance becomes excessive the performance of multi-phase machines can be impaired. When voltage unbalance occurs, the root mean square values of the line voltage on the motor phases will be unequal. For a three phase supply, a situation in which the magnitude of each of the phase voltage are not equal or when the phase angle between the phases deviates from the normal $120^{\circ}$, or when both conditions simultaneously occur is known as voltage unbalance [1].

Voltage unbalance creates negative sequence voltage. This negative sequence voltage creates a

\begin{abstract}
:
The performance of a three-phase induction motor operating under supply unbalance conditions has been the focus of many research works using various methods. Most of the studies have focused majorly on voltage magnitude unbalance without due analysis to determine the effect of deviations in the supply phase angle from the $120^{\circ}$ phase to phase displacement. This research investigates the significance of supply phase shift on the performance of a three-phase induction motor by applying a novel phase shift unbalance definition to the zero, negative and positive sequence components model of the motor. The test results reveal that when both phase angle shift and voltage magnitude unbalance occur simultaneously during motor operation the effect of the phase shift dominates over the effects of the voltage magnitude unbalance. This study shows that phase angle unbalance has a severe consequence on three phase motor performance.
\end{abstract}

magnetic flux that rotates in the opposite direction of the main flux, resulting in torque and power oscillation at double the frequency of the supply. It also, generates excessive negative sequence winding currents which culminate in increased motor loss, reduced efficiency, hot spot formation in the stator windings, and motor overheating [2-7]. A number of times the excessive current is mistakenly associated with winding failure [8].

Induction motors are the major backbone of many industrial processes; which are required to deliver optimum reliable performance. Often, induction machines are exposed to unbalanced supply voltage; a major power quality issue that impairs motor performance [4]. To mitigate against the negative effects of supply imbalance on motor performance, motor de-rating guidelines using voltage unbalance

\footnotetext{
* Corresponding author.

E-mail address: aderibigbe.adekitan@covenantuniversity.edu.ng.
} 
factor was proposed by the National Electrical Manufacturer Association (Standard NEMA MG 12003) and the International Electro-technical Commission (IEC Standard 60034-1). These standards have inherent limitations in their applicability and accuracy $[1,5,9,10]$ and one major issue is that different combinations of unbalance voltages may yield identical voltage unbalance factor, and also for the same voltage sample the standards may give different levels of unbalance.

The effects of voltage unbalance on induction motors has been studied using different methodologies such as finite element analysis, experimental motor tests, dq0 transformation approach, harmonic distortion studies, thermal models, vibration analysis [5, 11-14] etc. According to [12], the major focus of a number of research studies on voltage unbalance has been centred on voltage magnitude unbalance [15-18] without any consideration for the effects of phase angle unbalance or preferably supply phase shift on the induction motor. This paper explores the significance of phase shift on induction motor performance using the phase frame approach for motor component analysis [9]. The phase frame analysis is a methodology for directly analysing sequence component using phase terms without the need for successive parameter conversion from phase to sequence and back to phase form.

\section{Voltage unbalance}

Voltage unbalance may be caused by heavy commercial loads $[19,20]$, motor and power supply related factors. Some of the established root causes of voltage imbalance includes blown fuses on threephase capacitor banks, asymmetrical transformer winding impedances, grounds and faults in the transformer, unequal power supply line impedances which may be due to partial transposition of the transmission line, unequal transformer tap settings, open delta and open wye transformers and commonly, the unequal sharing of single phase loads across the supply phases, and also according to [21] the amount of single-phase loads relative to the threephase load [6, 21].

The excessive current associated with voltage unbalance results in excessive heat build-up [22] which may damage the insulation and ultimately destroy the motor. As shown in Fig. 1, starting with a balanced voltage, there is a significant increase in motor temperature as voltage unbalance increases [23].

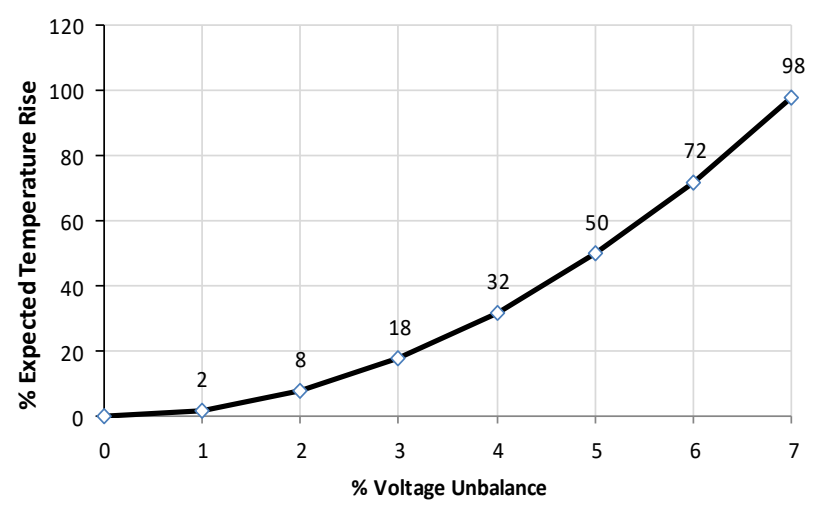

Figure 1. Percentage rise in temperature due to voltage unbalance [23].

Induction motors by design can tolerate a reasonable level of voltage unbalance, but for excessive level of unbalance the motor must be de-rated, otherwise the lifespan of the motor would be drastically reduced. Harmonics related with voltage unbalance reduces the efficiency of an induction motor due to increase in the motor winding harmonic current related losses, according to the study by [12] voltage unbalance in the extreme case can reduce motor life span to about $47 \%$ as compared with a nominal supply life span; and this is further aggravated to about $42 \%$ when the effect of total harmonic distortion of $8 \%$ is considered.

From the consumers' end, the reduction in efficiency implies increased energy charges due to the unbalanced voltage, and likewise the operation of a motor with reduced efficiency translates to an increased system load for the power plant and a reduction of the power plant's power reserve [24].

\subsection{Voltage unbalance definitions}

\section{- IEC Definition}

This is the adopted definition by IEC 60034-26 and it is referred to as the Voltage Unbalance Factor $(V U F)$ [25]. $V U F$ is the ratio of the negative-sequence voltage $\left(V_{2}\right)$ to the positive-sequence voltage $\left(V_{1}\right)$ :

$$
\operatorname{VUF}(\%)=K_{\mathrm{v}}=\frac{V_{2}}{V_{1}} \cdot 100 \%
$$

As defined by [25], given the line voltage $V_{\mathrm{ab}}, V_{\mathrm{bc}}$ and $V_{\text {ca, }}$, the $V U F$ can also be expressed as

$$
V U F=\frac{V_{2}}{V_{1}}=\sqrt{\frac{1-\sqrt{3-6 \beta}}{1+\sqrt{3-6 \beta}}}
$$


where

$$
\beta=\frac{V_{\mathrm{ab}}^{4}+V_{\mathrm{bc}}^{4}+V_{\mathrm{ca}}^{4}}{\left(V_{\mathrm{ab}}^{4}+V_{\mathrm{bc}}^{4}+V_{\mathrm{ca}}^{4}\right)}
$$

According to [4], in order to carry out an accurate unbalance analysis, all possible unbalance voltage combinations must be considered for any given percentage of unbalance as depicted in Fig. 2 which shows different voltage combinations of $220 \mathrm{~V}$ at $6 \%$ unbalance using IEC definition.

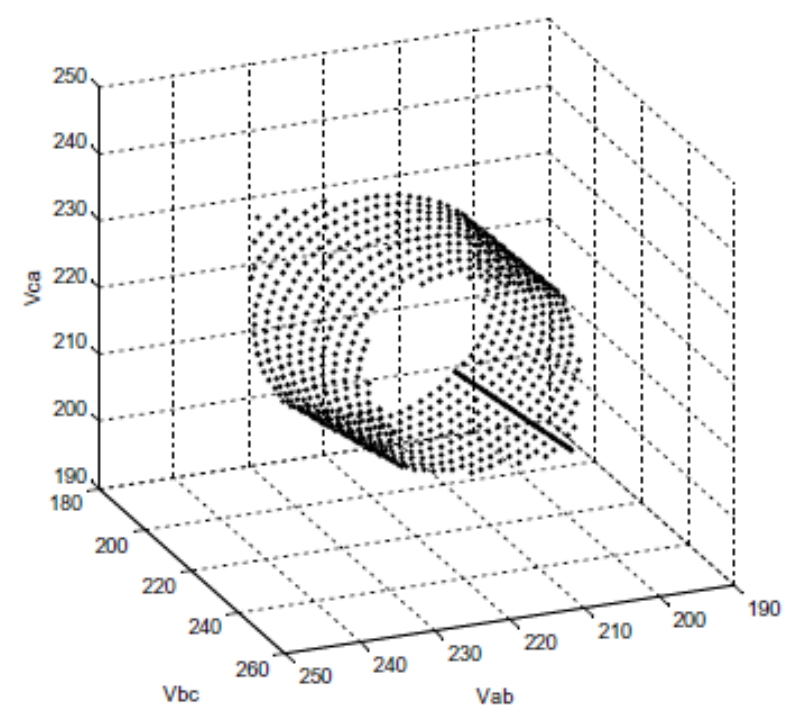

Figure 2. Potential voltage combinations for a $220 \mathrm{~V}$, 3 -phase induction motor with $6 \%$ unbalance [4].

- Complex Voltage Unbalance Factor (CVUF)

The extent of voltage variation due to IEC definition can be reduced by applying complex voltage unbalance factor. This definition accounts for the phase angle $\theta$ of the unbalance in addition to the unbalance voltage magnitude and it is defined as

$$
C V U F=V U F \angle \theta=K_{\mathrm{v}} \angle \theta=\frac{V_{2}}{V_{1}}, \angle \theta
$$

Previous studies that applied the CVUF usually assumes a fixed $K_{\mathrm{v}}$ so that the value of $\theta$ can be varied within a desired range as a reflection of the effect of $\theta$ during voltage unbalance conditions, but the use of $\theta$ as an accurate index is limited because different angular variation between $V_{2}$ and $V_{1}$ can give the same $\theta$ i.e. $\theta_{2}-\theta_{1}$ in complex polar notation.
In operational conditions when voltage unbalance occurs, more often than not, the deviation in line voltage from the rated value does not stay constant as the line voltage deviation may vary continuously due to load variations within and around the facility. To fully account for this, a method that allows for voltage magnitude variation while the phase angle unbalance is also taking place is desirable.

For this study, The NEMA definition will be applied for voltage magnitude unbalance while a novel phase angle unbalance definition given in (5) will be applied to study the effect of the phase shift on motor performance:

$$
\text { Ph. Unbal. }(\%)=\frac{\text { Max. ph. dev. from nom } . \text { value }}{120^{\circ}} \cdot 100 \%
$$

Equation (5) can be rewritten as:

$$
=\frac{\operatorname{Max}\left[\left|\angle a b-0^{\circ}\right|,\left|\angle b c-240^{\circ}\right|,\left|\angle c a-120^{\circ}\right|\right]}{\angle 120^{\circ}} \cdot 100 \%
$$

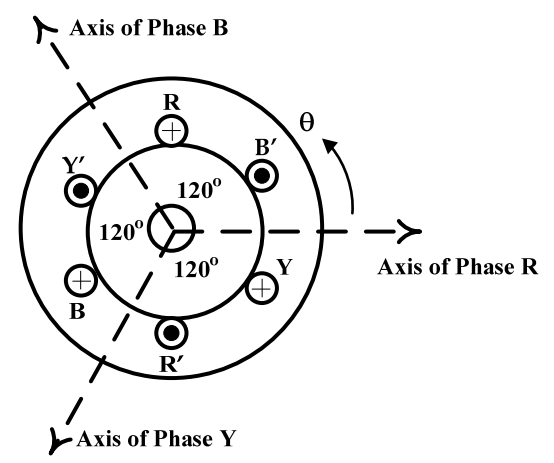

Figure 3. The relative location of the magnetic axis of a three-phase machine under a balanced voltage supply.

Each line voltage of a three-phase voltage supply should be displaced from the next by $120^{\circ}$ phase angle as shown in Fig. 3. When phase unbalance exists the phase angle between the line voltages deviates from the norm.

\section{The motor model}

In this research, the effects of supply phase shift is studied using the symmetrical component approach based on the positive, negative, and zero sequence equivalent circuits of an induction motor $[4,5,18$, $26]$ as shown in Fig. 4, Fig. 5 and Fig. 6. 


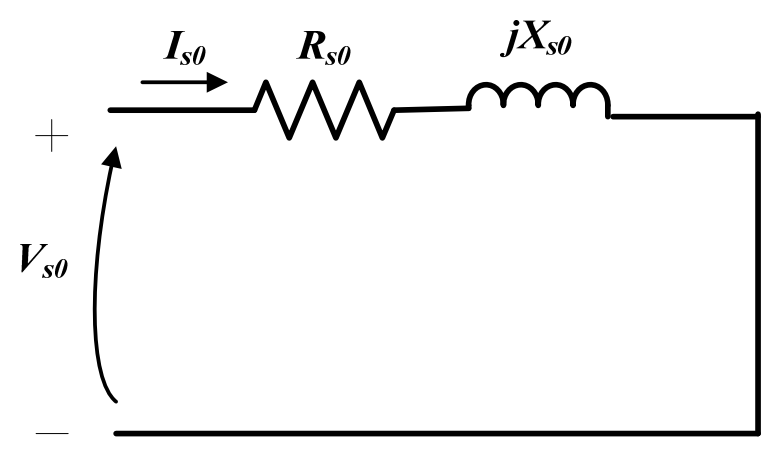

Figure 4. Per-phase zero sequence equivalent circuit of an induction motor.

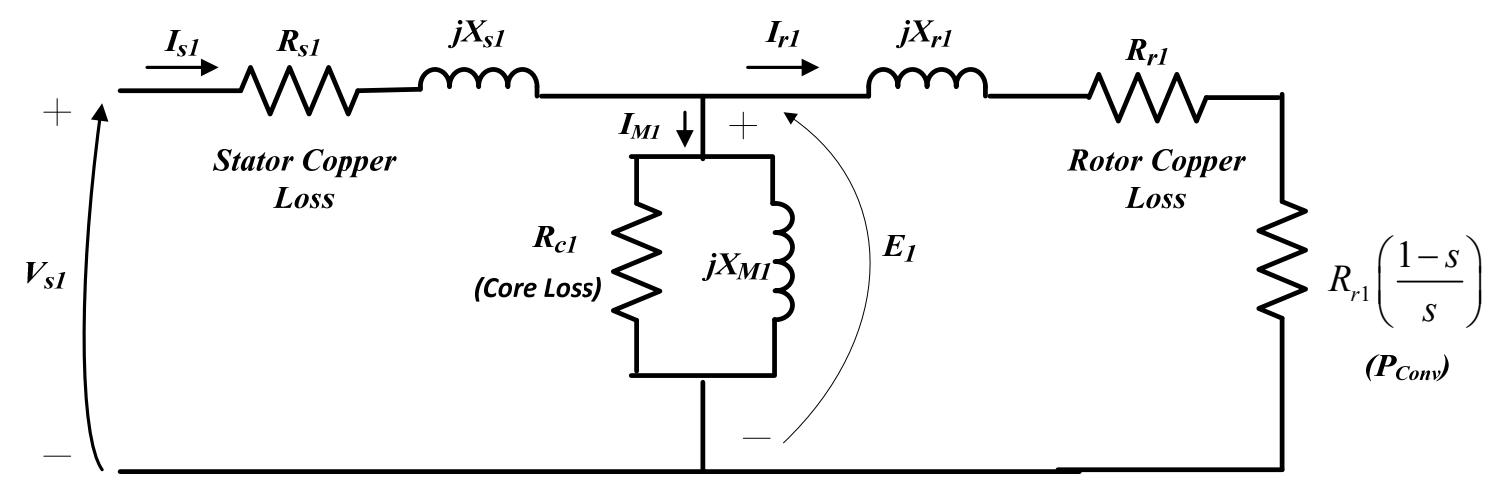

Figure 5. Per-phase positive sequence equivalent circuit of an induction motor.

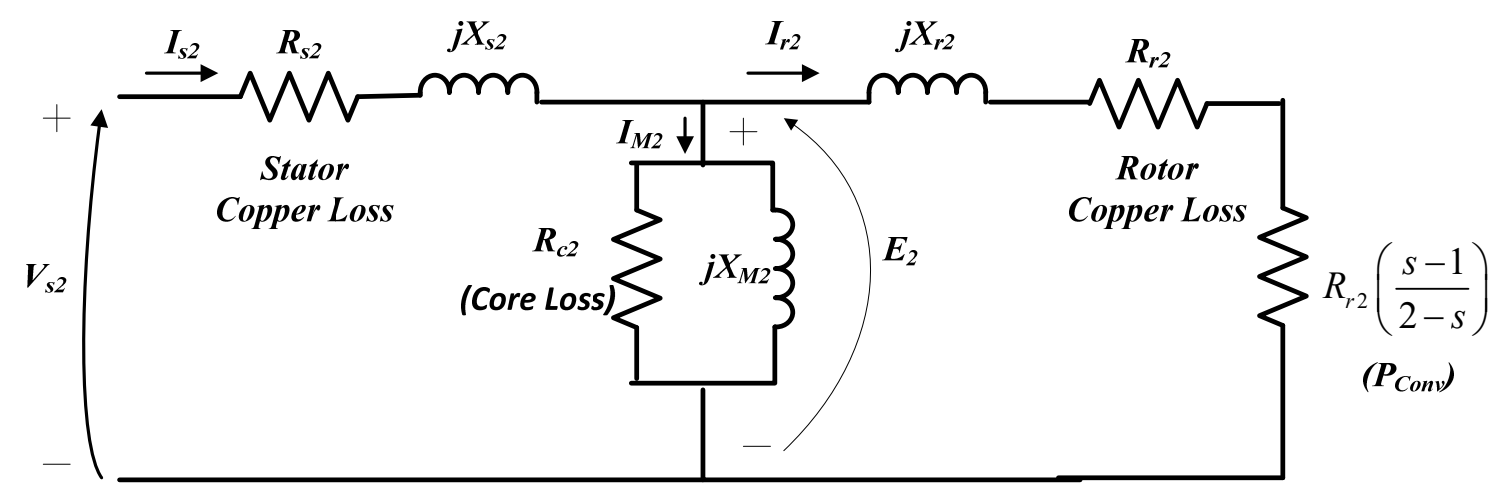

Figure 6. Per-phase negative sequence equivalent circuit of an induction motor.

The sequence impedances for the zero, positive, and negative sequence circuit is defined as $\underline{Z}_{0}, \underline{Z}_{1}$ and $\underline{Z}_{2}$

$$
\begin{aligned}
& \underline{Z}_{0}=R_{\mathrm{s} 0}+j X_{\mathrm{s} 0}=Z_{0} \angle \alpha_{0} \\
& \underline{Z}_{0}=Z_{0} \angle \alpha_{0}
\end{aligned}
$$

$$
\begin{aligned}
& \underline{Z}_{1}=R_{\mathrm{s} 1}+j X_{\mathrm{s} 1}+ \\
& +\frac{\left(j R_{\mathrm{c} 1} X_{\mathrm{m} 1}\right)\left(j X_{\mathrm{r} 1}+\frac{R_{\mathrm{r} 1}}{s}\right)}{j R_{\mathrm{c} 1} X_{\mathrm{m} 1}+\left(j X_{\mathrm{r} 1}+\frac{R_{\mathrm{r} 1}}{s}\right)\left(R_{\mathrm{c} 1}+j X_{\mathrm{m} 1}\right)} \\
& \underline{Z}_{1}=Z_{1} \angle \alpha_{1}
\end{aligned}
$$




$$
\begin{aligned}
& \underline{Z}_{2}=R_{\mathrm{s} 2}+j X_{\mathrm{s} 2} \\
& +\frac{\left(j R_{\mathrm{c} 2} X_{\mathrm{m} 2}\right)\left(j X_{\mathrm{r} 2}+\frac{R_{\mathrm{r} 2}}{2-s}\right)}{j R_{\mathrm{c} 2} X_{\mathrm{m} 2}+\left(j X_{\mathrm{r} 2}+\frac{R_{\mathrm{r} 2}}{2-s}\right)\left(R_{\mathrm{c} 2}+j X_{\mathrm{m} 2}\right)} \\
& \underline{Z}_{2}=Z_{2} \angle \alpha_{2}
\end{aligned}
$$

Using the Fortescue theorem transform the applied line voltage $V_{\mathrm{a}}, V_{\mathrm{b}}$ and $V_{\mathrm{c}}$ to sequence line voltage $V_{\mathrm{s} 0}$, $V_{\mathrm{s} 1} \angle \gamma_{1}$ and $V_{\mathrm{s} 2} \angle \gamma_{2}$ such that

$$
\begin{gathered}
\underline{I}_{0}=\frac{V_{\mathrm{s} 0}}{Z_{0}}=I s_{0} \angle-\alpha_{0} \\
\underline{I}_{1}=\frac{V_{\mathrm{s} 1}}{Z_{1}}=I s_{1} \angle \gamma_{1}-\alpha_{1} \\
\underline{I}_{2}=\frac{V_{\mathrm{s} 2}}{Z_{2}}=I s_{2} \angle \gamma_{2}-\alpha_{2} \\
I_{\mathrm{s}}=\left(\begin{array}{c}
I_{\mathrm{s} 0} \\
I_{\mathrm{s} 1} \\
I_{\mathrm{s} 2}
\end{array}\right) \text { and } V_{\mathrm{s}}=\left(\begin{array}{c}
V_{\mathrm{s} 0} \\
V_{\mathrm{s} 1} \\
V_{\mathrm{s} 2}
\end{array}\right)
\end{gathered}
$$

The stator phase currents is obtained from the sequence current equivalent as follows

$$
[I]_{\mathrm{Sabc}}=[A] \cdot[I]_{\mathrm{seq}}
$$

The transformation matrix $A$ in equation (14) is defined as

$$
\begin{gathered}
A=\left(\begin{array}{ccc}
1 & 1 & 1 \\
1 & a^{2} & a \\
1 & a & a^{2}
\end{array}\right) \\
a=1 \angle 120^{\circ}
\end{gathered}
$$

\subsection{Internal motor component analysis using the equivalent $T$ circuit}

To analyse the internal motor operation and determine parameters such as losses and air gap power, this paper applies the phase frame concept by [9]; removing the load resistance from the positive and negative sequence circuit of Fig. 5 and Fig. 6, an equivalent $\mathrm{T}$ circuit is developed which is analysed as follows.

$$
\begin{gathered}
Z_{\mathrm{m}}=R_{\mathrm{c}} / / j X_{\mathrm{m}}=\frac{j R_{\mathrm{c}} X_{\mathrm{m}}}{R_{\mathrm{c}}+j X_{\mathrm{m}}} \\
Y_{\mathrm{m}}=\frac{1}{Z_{\mathrm{m}}}
\end{gathered}
$$

Such that, for $i=1$ and 2 for positive and negative sequence component

The sequence stator impedance

$$
Z_{\mathrm{si}}=R_{\mathrm{si}}+j X_{\mathrm{si}}
$$

The sequence rotor impedance

$$
Z_{\mathrm{ri}}=R_{\mathrm{ri}}+j X_{\mathrm{ri}}
$$

The ABCD parameters of the equivalent T-circuit is given as

$$
\begin{gathered}
A_{\mathrm{i}}=\left(Y_{\mathrm{mi}} \times Z\right)_{\mathrm{si}}+1 \\
B_{\mathrm{i}}=\left(Y_{\mathrm{mi}} \times Z_{\mathrm{si}} \times Z_{\mathrm{ri}}\right)+Z_{\mathrm{si}}+Z_{\mathrm{ri}} \\
C_{\mathrm{i}}=Y_{\mathrm{mi}} \\
D_{\mathrm{i}}=\left(Y_{\mathrm{mi}} \times Z_{\mathrm{ri}}\right)+1 \\
\left(A_{\mathrm{i}} \times D_{\mathrm{i}}\right)-\left(B_{\mathrm{i}} \times C_{\mathrm{i}}\right)=1
\end{gathered}
$$

The stator and rotor sequence voltage and current components are related as shown in equations (26) and (27).

$$
\begin{gathered}
\left(\begin{array}{c}
V_{\mathrm{si}} \\
I_{\mathrm{si}}
\end{array}\right)=\left(\begin{array}{cc}
A_{\mathrm{i}} & B_{\mathrm{i}} \\
C_{\mathrm{i}} & D_{\mathrm{i}}
\end{array}\right)\left(\begin{array}{c}
V_{\mathrm{ri}} \\
I_{\mathrm{ri}}
\end{array}\right) \\
\left(\begin{array}{c}
V_{\mathrm{ri}} \\
I_{\mathrm{ri}}
\end{array}\right)=\left(\begin{array}{cc}
D_{\mathrm{i}} & -B_{\mathrm{i}} \\
-C_{\mathrm{i}} & A_{\mathrm{i}}
\end{array}\right)\left(\begin{array}{c}
V_{\mathrm{si}} \\
I_{\mathrm{si}}
\end{array}\right)
\end{gathered}
$$

For transformation from sequence to phase terms, equation (27) can be expressed as shown in equation (28).

$$
\left(\begin{array}{c}
V r_{\text {seq }} \\
I r_{\text {seq }}
\end{array}\right)=\left(\begin{array}{cc}
D_{\text {seq }} & B_{\text {seq }} \\
C_{\text {seq }} & A_{\text {seq }}
\end{array}\right)\left(\begin{array}{c}
V s_{\text {seq }} \\
I s_{\text {seq }}
\end{array}\right)
$$




$$
\begin{aligned}
& V r_{\text {seq }}=D_{\text {seq }} \times V s_{\text {seq }}+B_{\text {seq }} \times I s_{\text {seq }} \\
& I r_{\text {seq }}=C_{\text {seq }} \times V s_{\text {seq }}+A_{\text {seq }} \times I s_{\text {seq }}
\end{aligned}
$$

The rotor voltage and current values in phase terms are obtained as follows:

$$
\begin{gathered}
\left(\begin{array}{c}
V r_{\mathrm{abc}} \\
I r_{\mathrm{abc}}
\end{array}\right)=\left(\begin{array}{cc}
A D_{\mathrm{seq}} A^{-1} & A B_{\mathrm{seq}} A^{-1} \\
A C_{\mathrm{seq}} A^{-1} & A A_{\mathrm{seq}} A^{-1}
\end{array}\right)\left(\begin{array}{c}
V S_{\mathrm{abc}} \\
I s_{\mathrm{abc}}
\end{array}\right) \\
\left(\begin{array}{c}
V r_{\mathrm{abc}} \\
I r_{\mathrm{abc}}
\end{array}\right)=\left(\begin{array}{ll}
D_{\mathrm{abc}} & B_{\mathrm{abc}} \\
C_{\mathrm{abc}} & A_{\mathrm{abc}}
\end{array}\right)\left(\begin{array}{c}
V s_{\mathrm{abc}} \\
I S_{\mathrm{abc}}
\end{array}\right)
\end{gathered}
$$

\subsection{Motor performance measurement parameters}

As earlier established, the existence of voltage unbalance impacts the operation and performance of an induction motor. The extent and effect of this impact can be determined by monitoring key motor performance parameters; both electrical and mechanical.

For a three-phase induction motor, the magnetizing current is defined as:

$$
I m_{\mathrm{abc}}=I s_{\mathrm{abc}} \frac{\left(j X_{\mathrm{r}}+\frac{R_{\mathrm{r}}}{s}\right)}{\frac{j R_{\mathrm{c}} X_{\mathrm{m}}}{R_{\mathrm{c}}+j X_{\mathrm{m}}}+j X_{\mathrm{r}}+\frac{R_{\mathrm{r}}}{s}}
$$

The total input power into the motor, stator copper loss, rotor copper loss, and electromagnetic power are defined as follows:

$$
\begin{aligned}
& P_{\text {in }}=3\left(\frac{V_{0}^{2}}{\left|Z_{\text {eq } 0}\right|} \cos \left(-\alpha_{0}\right)+\frac{V_{1}^{2}}{\left|Z_{\text {eq } 1}\right|} \cos \left(\gamma_{1}-\alpha_{1}\right)\right. \\
& \left.+\frac{V_{2}^{2}}{\left|Z_{\text {eq2 } 2}\right|} \cos \left(\gamma_{2}-\alpha_{2}\right)\right) \\
& P_{\mathrm{s}}=\frac{\left|V s_{\mathrm{a}}\right|^{2}}{R_{\mathrm{sa}}}+\frac{\left|V s_{\mathrm{b}}\right|^{2}}{R_{\mathrm{sb}}}+\frac{\left|V s_{\mathrm{c}}\right|^{2}}{R_{\mathrm{sc}}} \\
& P_{\mathrm{r}}=\frac{\left|V r_{\mathrm{a}}\right|^{2}}{R_{\mathrm{ra}}}+\frac{\left|V r_{\mathrm{b}}\right|^{2}}{R_{\mathrm{rb}}}+\frac{\left|V r_{\mathrm{c}}\right|^{2}}{R_{\mathrm{rc}}}
\end{aligned}
$$

$$
P_{\mathrm{EM}}=\operatorname{Real}\left[V r_{\mathrm{a}} \cdot I r_{\mathrm{a}}^{*}+V r_{\mathrm{b}} \cdot I r_{\mathrm{b}}^{*}+V r_{\mathrm{c}} \cdot I r_{\mathrm{c}}^{*}\right]
$$

According to [27], the positive and negative sequence power can be obtained from the following equations:

$$
\begin{aligned}
& P_{\mathrm{p}}=3 I_{\mathrm{r} 1}{ }^{2} \frac{R_{\mathrm{r}}(1-s)}{s} \\
& P_{\mathrm{n}}=3 I_{\mathrm{r} 2}{ }^{2} \frac{R_{\mathrm{r}}(s-1)}{2-s}
\end{aligned}
$$

The positive and negative sequence torque $T_{\mathrm{p}}$ and $T_{\mathrm{n}}$ component are defined as follows:

$$
\begin{gathered}
T_{\mathrm{p}}=\frac{P_{\mathrm{p}}}{W_{\mathrm{m}}}=\frac{P_{\mathrm{p}}}{W_{\mathrm{s}}(1-s)}=3 I_{\mathrm{r} 1}{ }^{2} \frac{R_{\mathrm{r}}}{s W_{\mathrm{s}}} \\
T_{\mathrm{n}}=\frac{P_{\mathrm{n}}}{W_{\mathrm{m}}}=\frac{P_{\mathrm{n}}}{W_{\mathrm{s}}(1-s)}=3 I_{\mathrm{r} 2}^{2} \frac{R_{\mathrm{r}}}{(2-s) W_{\mathrm{s}}}
\end{gathered}
$$

where $s$ is the motor slip.

\section{Analyses of the effects of phase shift on 3- phase motor performance}

In order to achieve this, a study was carried out using a 4 pole, 3-phase, $415 \mathrm{~V}, 25 \mathrm{~kW}$ induction motor with the following per unit parameters for each phase: stator winding resistance $R_{\mathrm{s}}=0.1134 \Omega$, rotor winding resistance $R_{\mathrm{r}}=0.1907 \Omega$, core loss resistance $R_{c}=\infty$, stator winding leakage reactance $X_{\mathrm{S}}=0.2268 \Omega$, rotor winding leakage reactance $X_{\mathrm{r}}=0.2268 \Omega$, magnetizing reactance $X_{\mathrm{m}}=9.0703 \Omega$ and the nominal slip at the rated full load speed is 0.0355 . All circuit parameters are assumed constant. In the analysis, the percentage voltage magnitude unbalance is varied up to $10 \%$ to allow for the motor performance study beyond the NEMA recommended $5 \%$.

Setup I: Performance characteristics of a three phase induction motor working under balanced line voltage magnitude, but with supply phase shift.

A major factor which is not often considered during motor unbalance studies is phase unbalance. For a three-phase voltage supply to have a balanced phase, each successive line voltage must be displaced from the next by $120^{\circ}$ phase angle. When phase unbalance exists the phase angle between the line voltages do vary. It is therefore imperative to study how supply 
phase unbalance can impact induction motor performance even when the line voltage magnitudes are balanced.

To achieve this, a simulation was carried out; using phase angle variation within the range of $0^{\circ}-30^{\circ}$ (25\% phase unbalance) as defined by equation (6). Two cases were considered as detailed below:

Case A: Let the phase angle of Line voltage $V_{\mathrm{ab}}$ remain constant while the phase angle of $V_{\mathrm{bc}}$ is varied between $-120^{\circ}$ to $-90^{\circ}$. The phase angle of Line voltage of $V_{\text {ca }}$ alternates from $90^{\circ}$ to $120^{\circ}$.

Case B: Let the phase angle of Line voltage $V_{\mathrm{ab}}$ remain constant while the phase angle of $V_{\mathrm{bc}}$ alternates between $-120^{\circ}$ to $-135^{\circ}$. The phase angle of Line voltage $V_{\text {ca }}$ is varied from $120^{\circ}$ to $150^{\circ}$.

Setup II: Performance characteristics of a three phase induction motor working under simultaneous unbalance voltage magnitude and unbalance phase shift condition.

Using the Case B of setup I, as basis for phase shift; simultaneously existing with the phase angle unbalance is a regime of voltage magnitude unbalance of $10 \%$ voltage deviation. Line voltage $V_{\mathrm{bc}}$ is decreased below the nominal value while $V_{\mathrm{ab}}$ is reduced at about $40 \%$ of the rate at which $V_{\mathrm{bc}}$ is reduced. The magnitude of $V_{\text {ca }}$ is increased at twice the rate at which $V_{\mathrm{ab}}$ is reduced.

The diagram in Fig. 7 shows comparatively, the difference between a balanced voltage and an unbalance voltage.

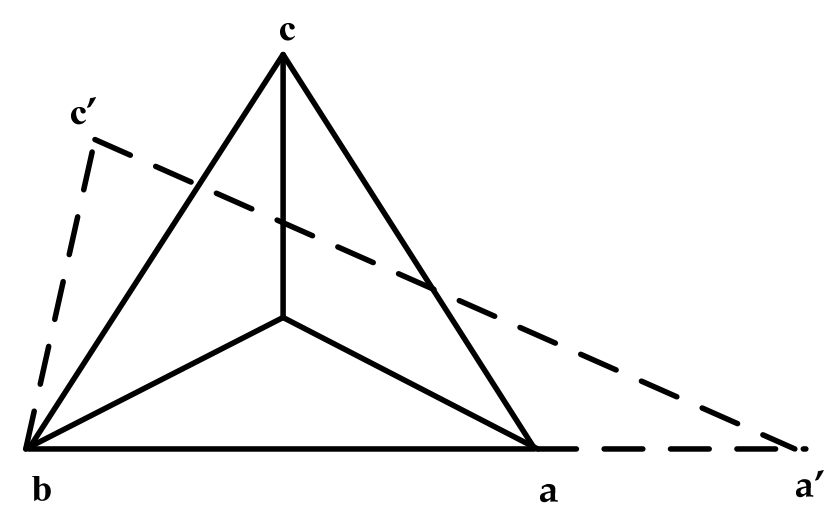

Figure 7. Balanced versus unbalance 3-phase voltage.

\subsection{The Result and Analysis}

The graphs of Fig. 8 to Fig. 17 represent the results of some of the different motor performance parameter considered for the various levels of unbalance. The values are expressed as a percentage of the parameter's value when the voltage and/or phase is balanced.

As detailed in Table 1 for the phase shift, when the rotor phase A loss is 7.3\% (10\% Unbalance) and $326 \%$ (25\% Unbalance) for Case A, for Case B it is $410 \% \quad(10 \% \quad$ Unbalance $)$ and $1363 \% \quad(25 \%$ Unbalance) respectively, whereas for the stator, when the stator phase A loss is $27 \%$ ( $10 \%$ Unbalance) and $260 \%$ (25\% Unbalance) for Case A, for Case B it is $355 \% \quad(10 \% \quad$ Unbalance $)$ and $1079 \% \quad(25 \%$ Unbalance) respectively. The variation in result between the cases, emphasizes the significance of the nature of the unbalance and the associated increase in losses as phase shift unbalance increases.

\section{Setup I result}

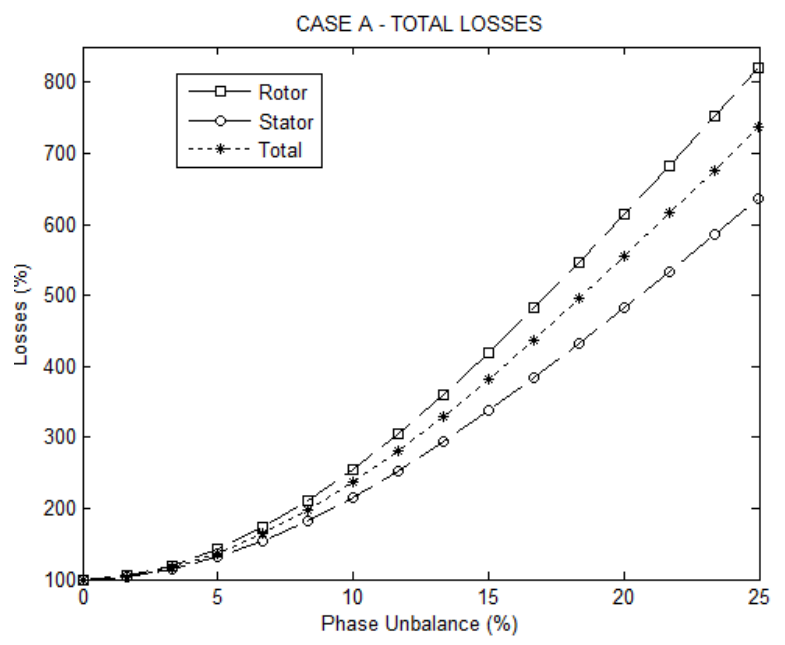

Figure 8. Total Winding Copper Loss.

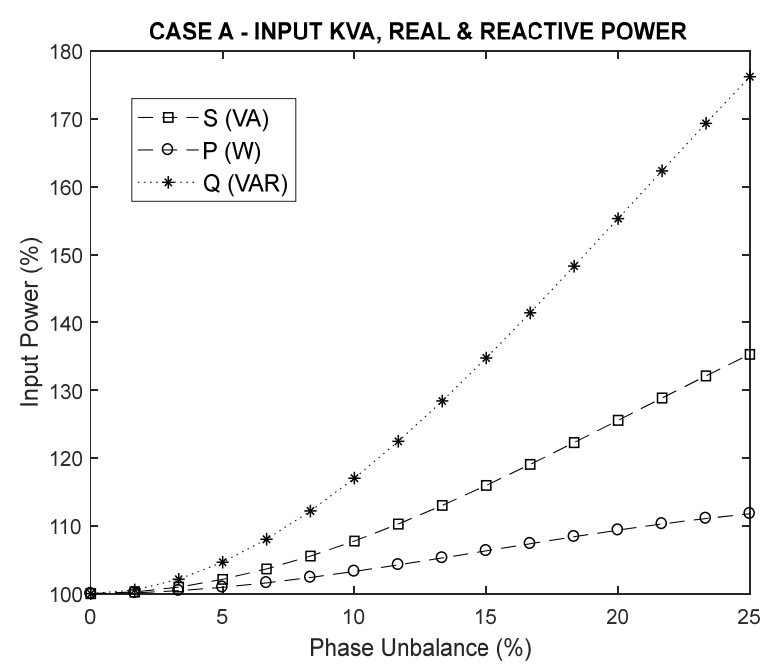

Figure 9. Power components variation with change in voltage unbalance. 


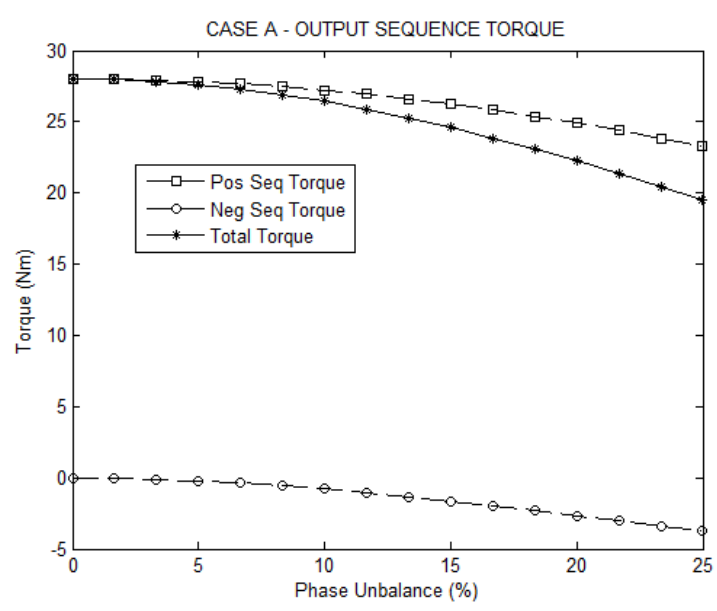

Figure 10. Sequence Torque variation in consonance with the unbalance.

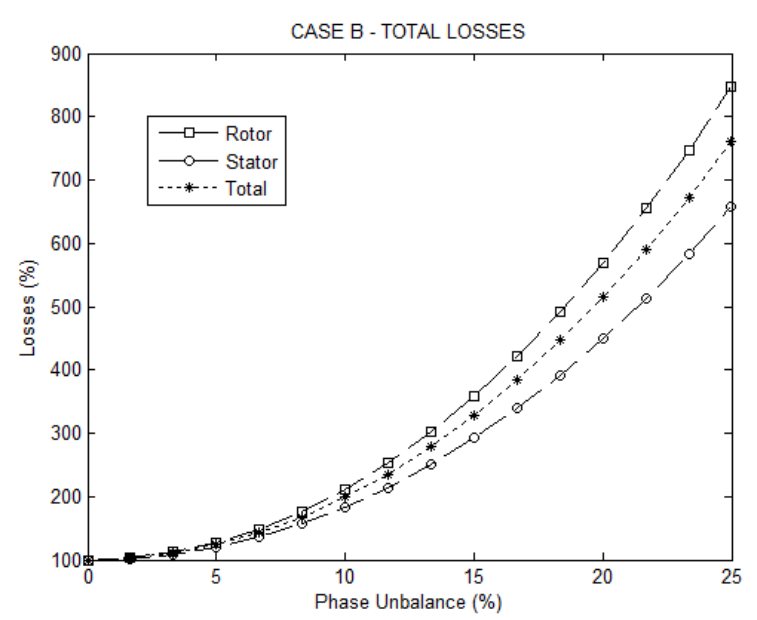

Figure 11. Total Winding Copper Loss.

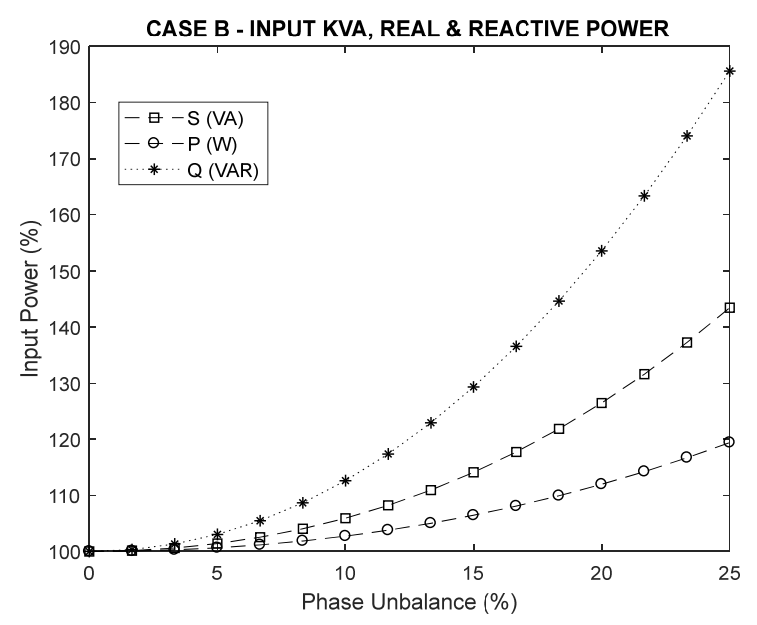

Figure 12. Power components variation with change in voltage unbalance.

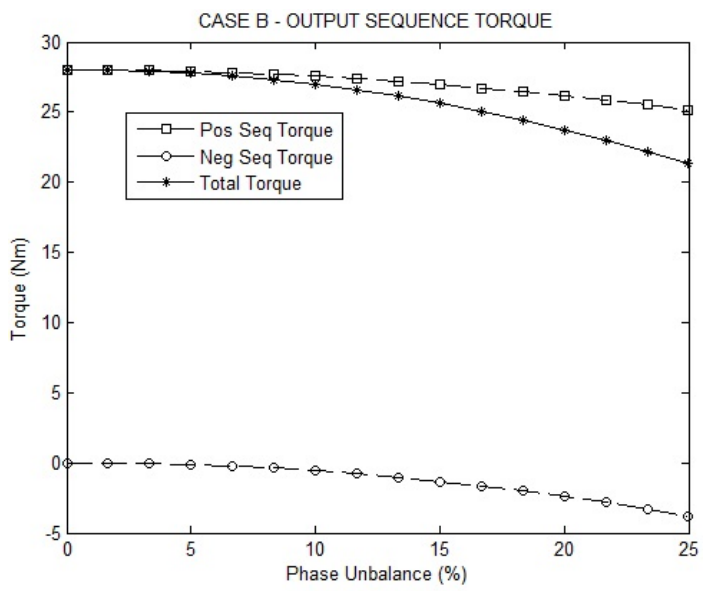

Figure 13. Sequence Torque variation in consonance with the unbalance.

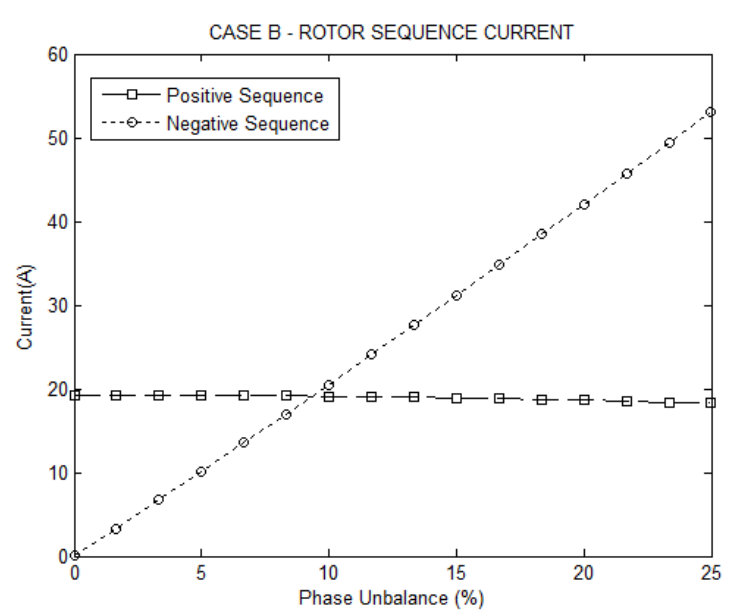

Figure 14. Rotor Sequence Current.

\section{Setup II Result}

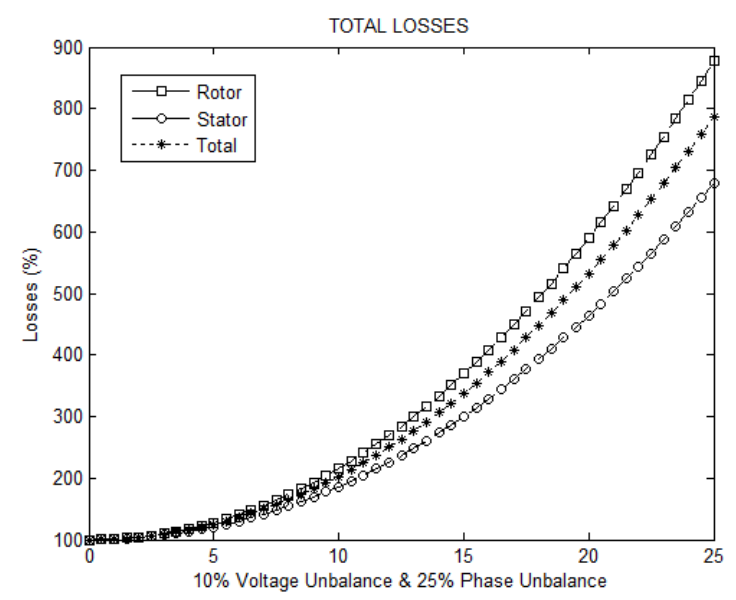

Figure 15. Total Winding Copper Loss 


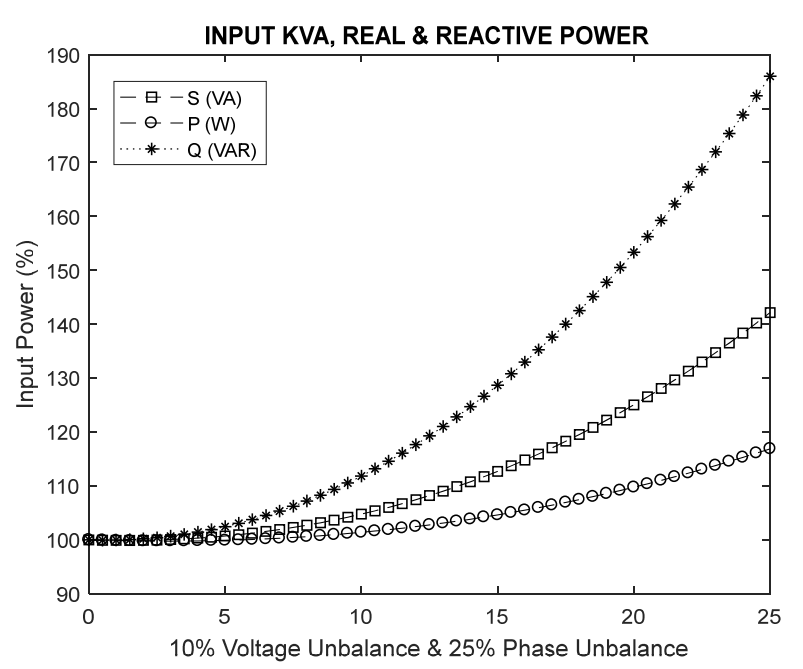

Figure 16. Power components variation with change in voltage unbalance.



Figure 17. Sequence Torque variation in consonance with the unbalance.

For easy comparative analysis, the values of the motor parameters specifically at 5\% and $10 \%$ magnitude unbalance and at $10 \%$ and $25 \%$ phase shift is compiled in Table 1 and Table 2 . The values are extracted from the result dataset as the voltage magnitude unbalance varied from $0-10 \%$ and the phase magnitude unbalance varied from $0-25 \%$.

Table 1 shows that, for the phase shift, the variation in the magnetizing current is maximum for the phase $\mathrm{C}$ of Case $\mathrm{B}$ with a reduction in magnetising current from $94.30 \%$ (10\% Unbalance) to $82.14 \%$ (25\% Unbalance). For phase B of Case A there is a reduction in magnetising current from $95 \%(10 \%$ Unbalance) to $84 \%$ ( $25 \%$ Unbalance), whereas for
Phase B of Case B the current reduction is from $101.24 \% \quad(10 \%$ Unbalance) $)$ to $100.94 \% \quad(25 \%$ Unbalance). Maximum variation in output power for the rotor occurred in phase $\mathrm{B}$ and phase $\mathrm{C}$ of Case A with a reduction from $95 \%$ to $77 \%$, while there is a slight increase from $100.35 \%$ to $103.45 \%$ for phase A of Case B. This variation between Case A and Case $B$ also shows that the manner of the phase unbalance determines the effect on the motor.

A very significant variation from the balanced state is observed for the negative sequence motor torque per rotor winding. The variation of the negative sequence torque for Case B is from $0.57 \mathrm{Nm}(10 \%$ Unbalance) to $3.84 \%$ (25\% Unbalance) and this caused a reduction of the positive sequence torque from $26.98 \mathrm{Nm}$ (10\% Unbalance) to $21.31 \mathrm{Nm}(25 \%$ Unbalance). This represents a maximum drop of $89.75 \%$ ( 0 to $25 \%$ Unbalance) for the positive sequence torque due to the generation of negative sequence torque. Likewise, for the Case $\mathrm{B}$, the positive sequence rotor current varied slightly from 19.28A to $17.56 \mathrm{~A}$, while the negative sequence rotor current rose from zero to 53.07A. This is a confirmation that the main effect of voltage unbalance is significantly on the negative sequence components.

From the winding loss variations it is observed that for Case A as the phase shift unbalance is increased from $10 \%$ to $25 \%$, the total rotor loss changed by $322 \%$, while for Case B it changed by $401 \%$. The total stator loss for Case A changed by $295.8 \%$ while for Case B it changed by $359.6 \%$. This shows that the rotor suffers more from winding losses induced by voltage unbalance. The data in Table 1, also shows a significant reduction in power factor and motor efficiency for the phase shift unbalance as compared with the voltage magnitude unbalance. Also, there is an increase in reactive power and apparent power for the phase shift unbalance as compared with the voltage magnitude unbalance which indicates increased energy consumption for the same useful work.

A remarkable observation from the result is the increase in the percentage change in parameter values when the $10 \%$ Voltage Magnitude Unbalance result for the winding losses, reactive power, and negative sequence current is compared with the $10 \%$ phase shift results of Case A and Case B in Table 1. The percentage change is more than double for some parameters, from these results it can be inferred that

(a) Phase unbalance affects motor performance characteristics 
(b) The manner and magnitude of the phase unbalance determines the impact on the motor performance

(c) For same percentage of unbalance, phase shift unbalance has more impact on the negative sequence components and the motor losses than voltage magnitude unbalance

Table 1: Simulation I Result

\begin{tabular}{|c|c|c|c|c|c|c|}
\hline \multirow[b]{3}{*}{ MOTOR PARAMETERS } & \multicolumn{2}{|c|}{$\begin{array}{l}\text { Voltage Magnitude } \\
\text { Unbalance Only }\end{array}$} & \multicolumn{4}{|c|}{ Phase Shift Only (Setup 1) } \\
\hline & \multirow[b]{2}{*}{ @5\% } & \multirow[b]{2}{*}{$@ 10 \%$} & \multicolumn{2}{|c|}{ CASE A } & \multicolumn{2}{|c|}{ CASE B } \\
\hline & & & $@ 10 \%$ & $@ 25 \%$ & $@ 10 \%$ & $@ 25 \%$ \\
\hline Phase A Rotor Loss (\%) & 95 & 107 & 7.3 & 326 & 410 & 1363 \\
\hline Phase B Rotor Loss (\%) & 63 & 45 & 375 & 1073 & 75 & 524 \\
\hline Phase C Rotor Loss (\%) & 162 & 240 & 375 & 1062 & 140 & 654 \\
\hline Phase A Stator Loss (\%) & 120 & 153 & 27 & 260 & 355 & 1079 \\
\hline Phase B Stator Loss (\%) & 55 & 24 & 220 & 646 & 148 & 588 \\
\hline Phase C Stator Loss (\%) & 138 & 189 & 398 & 1001 & 45 & 306 \\
\hline Total Rotor Loss (\%) & 107 & 131 & 254 & 820 & 211 & 847 \\
\hline Total Stator Loss (\%) & 105 & 122 & 215 & 636 & 183 & 658 \\
\hline Total Winding Loss (\%) & 106 & 127 & 236 & 736 & 198 & 761 \\
\hline Ph A Magnetising Current & 100.08 & 100.16 & 97 & 86 & 102.08 & 102.32 \\
\hline $\mathrm{Ph}$ B Magnetising Current (\%) & 97.75 & 95.51 & 95 & 84 & 101.24 & 100.94 \\
\hline Ph C Magnetising Current (\%) & 99.18 & 98.38 & 104 & 103 & 94.3 & 82.14 \\
\hline Phase A Power (\%) & 98.17 & 96.67 & 99.9 & 96.2 & 100.35 & 103.45 \\
\hline Phase B Power (\%) & 97.93 & 95.73 & 95 & 77 & 97.3 & 83.7 \\
\hline Phase C Power (\%) & 97.93 & 95.73 & 95 & 77 & 97.3 & 83.7 \\
\hline Input Real Power (\%) & 98.35 & 97.40 & 103 & 111 & 102.7 & 119.4 \\
\hline Input Reactive Power (\%) & 99.11 & 100.43 & 117 & 176 & 112.6 & 185.5 \\
\hline Input KVA (\%) & 98.59 & 98.35 & 107 & 135 & 105.9 & 143.4 \\
\hline Air Gap Power (\%) & 98.17 & 96.67 & 99.95 & 96.26 & 100.35 & 103.45 \\
\hline Power Factor (\%) & 99.76 & 99.03 & 96 & 82 & 97 & 83.2 \\
\hline Positive Seq. Torque (Nm) & 27.47 & 26.92 & 27.20 & 23.20 & 26.98 & 21.31 \\
\hline Negative Seq. Torque (Nm) & -0.04 & -0.18 & -0.80 & -3.73 & -0.57 & -3.84 \\
\hline Motor Efficiency (\%) & 93.21 & 91.77 & 85 & 58 & 87.8 & 60 \\
\hline
\end{tabular}

A comparative study of the Voltage Magnitude Unbalance Only simulation results in Table 1 and Table 2 simulation results, reveals what happens when voltage magnitude unbalance and phase angle unbalance occur simultaneously. The result shown in Table 2 is closer in magnitude to the Case B result in Table 1, which reflects the dominance of the phase shift unbalance over voltage magnitude unbalance. General conclusions from the simulation results:

i. In line with the assertion of [28] that the "unique value of the performance parameters of the 3-phase induction motor does not depend only on the degree of voltage unbalance but also on information about the condition of the unbalance". This research work has similarly established same result that the impact of the unbalance on the induction motor is highly determined by the nature of the unbalance.

ii. Deviation in voltage phase angle which results in phase shift is a major induction motor performance determinant. The phase unbalance stimulates excessive increase in the negative sequence components and 
reactive power, which increases power consumption and energy charge for the same useful work.

iii. When a voltage magnitude unbalance condition is simultaneously associated with a regime of supply phase angle unbalance, the effect of the phase unbalance is more prominent than the impact of the voltage magnitude unbalance on the induction motor. Hence, for a detailed an accurate motor performance assessment, the phase angle variations must be duly factored into performance study of motors operating under unbalance conditions.

iv. Motor losses increase significantly at a greater rate as the percentage of unbalance rises, resulting in excessive heat generation, energy waste, and winding insulation weakening. This translates to a reduction in efficiency and an increase in power consumption and energy cost [29].

v. As the percentage of voltage unbalance increases, there is a greater increase of the total rotor loss than the increase in the total stator loss.

Table 2: Simulation II Result

\begin{tabular}{|c|c|c|}
\hline \multirow[b]{2}{*}{ MOTOR PARAMETERS } & \multicolumn{2}{|c|}{ Simultaneous Voltage and Phase Unbalance (Setup 2) } \\
\hline & $\begin{array}{l}\text { Result at } 10 \% \text { (Phase) \& } 4 \% \\
\text { (Magnitude) Unbalance }\end{array}$ & $\begin{array}{c}\text { Result at } 25 \% \text { (Phase) \& } 10 \% \\
\text { (Magnitude) Unbalance }\end{array}$ \\
\hline Phase A Rotor Loss (\%) & 413 & 1361 \\
\hline Phase B Rotor Loss (\%) & 42 & 465.4 \\
\hline Phase C Rotor Loss (\%) & 191.3 & 800.64 \\
\hline Phase A Stator Loss (\%) & 369.59 & 1121 \\
\hline Phase B Stator Loss (\%) & 109 & 504 \\
\hline Phase C Stator Loss (\%) & 78 & 408 \\
\hline Total Rotor Loss (\%) & 216 & 876 \\
\hline Total Stator Loss (\%) & 186 & 679 \\
\hline Total Winding Loss $(\%)$ & 202 & 786 \\
\hline $\mathrm{Ph}$ A Magnetising Current (\%) & 101.5 & 103 \\
\hline $\mathrm{Ph}$ B Magnetising Current (\%) & 99 & 96 \\
\hline $\mathrm{Ph} \mathrm{C}$ Magnetising Current (\%) & 94 & 81 \\
\hline Phase A Power (\%) & 98.6 & 98.7 \\
\hline Phase B Power (\%) & 95.7 & 80 \\
\hline Phase C Power (\%) & 95.7 & 80 \\
\hline Input Real Power (\%) & 101 & 116 \\
\hline Input Reactive Power (\%) & 111 & 185 \\
\hline Input KVA (\%) & 104 & 142 \\
\hline Air Gap Power (\%) & 98.88 & 100.26 \\
\hline Power Factor $(\%)$ & 96 & 82 \\
\hline Positive Sequence Torque (Nm) & 27 & 24 \\
\hline Negative Sequence Torque (Nm) & -0.605 & -4 \\
\hline Motor Efficiency (\%) & 87 & 57 \\
\hline
\end{tabular}

A comparative study of the Voltage Magnitude Unbalance Only simulation results in Table 1 and Table 2 simulation results, reveals what happens when voltage magnitude unbalance and phase angle unbalance occur simultaneously. The result shown in
Table 2 is closer in magnitude to the Case $\mathrm{B}$ result in Table 1, which reflects the dominance of the phase shift unbalance over voltage magnitude unbalance. General conclusions from the simulation results: 
vi. In line with the assertion of [28] that the "unique value of the performance parameters of the 3-phase induction motor does not depend only on the degree of voltage unbalance but also on information about the condition of the unbalance". This research work has similarly established same result that the impact of the unbalance on the induction motor is highly determined by the nature of the unbalance.

vii. Deviation in voltage phase angle which results in phase shift is a major induction motor performance determinant. The phase unbalance stimulates excessive increase in the negative sequence components and reactive power, which increases power consumption and energy charge for the same useful work.

viii. When a voltage magnitude unbalance condition is simultaneously associated with a regime of supply phase angle unbalance, the effect of the phase unbalance is more prominent than the impact of the voltage magnitude unbalance on the induction motor. Hence, for a detailed an accurate motor performance assessment, the phase angle variations must be duly factored into performance study of motors operating under unbalance conditions.

ix. Motor losses increase significantly at a greater rate as the percentage of unbalance rises, resulting in excessive heat generation, energy waste, and winding insulation weakening. This translates to a reduction in efficiency and an increase in power consumption and energy cost [29].

$\mathrm{x}$. As the percentage of voltage unbalance increases, there is a greater increase of the total rotor loss than the increase in the total stator loss.

\section{Conclusion}

This research has investigated the operational impact of supply phase shift on the performance of 3-phase induction motor. The phase shift unbalance causes a reduction in motor efficiency, developed torque, and motor power factor. It also leads to undesirable increase in reactive power consumption which increases energy cost.

In full agreement with [23], presently there are variations in the acceptable level of voltage unbalance as recommended by different standards. When voltage unbalance exists, the proactive and reliability centred approach is to perform a detailed root cause analysis on the system and facility towards deploying a corrective action on the root cause rather than dependence on motor de-rating only. A network audit should be periodically carried out to identify any existence of non-uniform single load distribution and to also correct same by feeder or line switching. By all means, voltage unbalance should be kept below the 5\% NEMA recommendation. Likewise, a percentage phase angle deviation of $4 \%$ is hereby proposed as a maximum limit.

\section{References}

[1] Pillay, P., Manyage, M., Definitions of voltage unbalance, IEEE Power Engineering Review, 21 (2001), 50-51.

[2] Berndt, M. M., Schmitz, N. L.: Derating of Polyphase Induction Motors Operated with Unbalanced Line Voltages, Transactions of the American Institute of Electrical Engineers Part III Power Apparatus and Systems 81 (1962), 3, $680-683$.

[3] Bossio, G. R., Angelo, C. H. D., Donolo, P. D., Castellino, A. M., Garcia, G. O.: Effects of voltage unbalance on IM power, torque and vibrations, IEEE International Symposium on Diagnostics for Electric Machines, Power Electronics and Drives, Cargèse, France, 2009, 1-6.

[4] Faiz, J., Ebrahimpour, H.: Precise derating of three-phase inducon motors with unbalanced voltages, Fourtieth IAS Annual Meeting, Conference Record of the 2005 Industry Applications Conference, 2005, 485-491.

[5] Donolo, P., Bossio, G., De Angelo, C.: Analysis of voltage unbalance effects on induction motors with open and closed slots, Energy Conversion and Management, 52 (2011), 2024-2030.

[6] Jouanne, A. V., Banerjee, B.: Assessment of voltage unbalance, IEEE Transactions on Power Delivery, 16 (2001), 782-790.

[7] Williams, J. E.: Operation of 3-Phase Induction Motors on Unbalanced Voltages, Transactions of the American Institute of Electrical Engineers Part III: Power Apparatus and Systems, 73 (1954), 1.

[8] Kostic-Perovic, D., Arkan, M., Unsworth, P.: Induction motor fault detection by space vector angular fluctuation, in Conference Record of 
the 2000 IEEE Industry Applications Conference. Thirty-Fifth IAS Annual Meeting and World Conference on Industrial Applications of Electrical Energy, 2000, 388394.

[9] Kersting, W. H., Phillips, W. H.: Phase Frame Analysis of the Effects of Voltage Unbalance on Induction Machines, IEEE Transactions on Industry Applications, vol. 32 (1997), 415-420.

[10] Pillay, P., Hofmann, P., Manyage, M.: Derating of induction motors operating with a combination of unbalanced voltages and over or undervoltages, IEEE Trans. Energy Conservation, 17 (2002).

[11] Gnacinski, P., Tarasiuk, T.: Energy-efficient operation of induction motors and power quality standards, Electric Power Systems Research, 135 (2016), 10-17.

[12] Gnacinski, P.: Effect of unbalanced voltage on windings temperature, operational life and load carrying capacity of induction machine, Energy Conversion and Management, 49 (2008),761770 .

[13] Ebadi, A., Mirzaie, M., Gholamian, S. A.: Investigation of the Effects of Unbalanced Voltages on the Performance of a Three-Phase Squirrel Cage Induction Motor using Finite Element Method, Majlesi Journal of Electrical Engineering; 7 (2013).

[14] Ebadi, S. A., Mirzaie, M., Zareinejad, Gholamian S. A.: Torque analysis of threephase induction motor under voltage unbalance using 2D FEM, 3 (2011).

[15] Kanwarjit, S. S., Vineet, C.: Simulations of Three- Phase Induction Motor Operating with Voltage Unbalance, in In Proceedings of the 8th WSEAS International Conference on Electric power systems, high voltages, electric machines, Venice, Italy, 2008.

[16] Yaw-Juen, W.: An analytical study on steadystate performance of an induction motor connected to unbalanced three-phase voltage, 2000 IEEE Power Engineering Society Winter Meeting. Conference Proceedings, 2000, 159164.

[17] Himanshu; P.: Steady State and Transient Performance Analysis of Three Phase Induction Machine using MATLAB Simulations vol. 1, 2009.

[18] Kini, G., Bansal, R., Aithal, R. S.: Impact of voltage unbalance on the performance of threephase induction motor, 24 (2006).
[19] Von Jouanne, A., Banerjee, B. B.: Voltage unbalance: Power qualityissues, related standards and mitigation techniques, Electric Power Research Institute, Palo Alto, CA, EPRI Final Rep, 2000.

[20] Woll, R.: Effect of unbalanced voltage on the operation of polyphase induction motors, IEEE Transactions on Industry Applications, (1975), 38-42.

[21] Kersting, W. H.: Causes and Effects of Unbalanced Voltages Serving an Induction Motor, Rural Electric Power Conference Louisville, KY, 2000.

[22] Gafford, B. N., Duesterhoeft, W. C., Mosher, C. C.: Heating of Induction Motors on Unbalanced, Power Apparatus and Systems, Part III. Transactions of the American Institute of Electrical Engineers, 78 (1959), 282-286.

[23] PGE (2009, 19 August 2015). Voltage Unbalance and Motors. Available: http://www.pge.com/includes/docs/pdfs/mybusi ness/customerservice/energystatus/powerqualit y/voltage_unbalance_rev2.pdf

[24] Faiz, J., Pillay, P., Influence of Unbalanced Voltage on the Steady-State Performance of a Three-Phase Squirrel-Cage Induction Motor, IEEE Transactions on energy conversion, 19 (2004), 657-62.

[25] Quispe, E., Vigeo, P., Cogollos, J.: Statistical equations to evaluate the effects of voltage unbalance on the efficiency and power factor of a three-phase induction motors, WSEAS Transactions On Circuits And Systems, Brasil, 4, 2005, 234 - 239.

[26] Fortescue, C. L.: Method of symmetrical coordinates applied to the solution of polyphase networks, AIEE Trans, 37 (1918), 1027-140.

[27]Faiz, J., Ebrahimpour, H., Pillay, P.: Influence of Unbalanced Voltage on the Steady-State Performance of a Three-Phase Squirrel-Cage Induction Motor, IEEE transactions on energy conversion, 19, 2004, 657-662.

[28] Abhishek, C., Padmanabh, T., Dogga, R.: Assessment of induction motor performance under supply voltage unbalance, Engineering and Systems (SCES), 2013 Students Conference, Allahabad, 2013.

[29] Annette, J. V., Basudeb, B. B.: Assessment of Voltage Unbalance, IEEE transactions on power delivery, 16, 2001. 